\title{
Critérios de investimentos como indutores da gestão integrada de recursos hídricos: um estudo de caso do Comitê da Bacia Hidrográfica do Alto Tietê, SP
}

\section{Investment criteria as inductors of integrated water resources management: Alto Tietê River Basin Committee (SP) case study}

\author{
Data de entrada: \\ 19/03/2019 \\ Data de aprovação: \\ 30/07/2019
}

Marcos Paulo Lallo Sartori ${ }^{*}$ | Antonio Carlos Zuffo²

ORCID ID

Sartori MPL (ID) https://orcid.org/0000-0001-8453-2060
DOI: https://doi.org/10.36659/dae.2020.077

Zuffo AC (D) https://orcid.org/0000-0002-2186-9755

\section{Resumo}

Diante de um cenário de aumento dos impactos ambientais sobre os recursos hídricos, e da escassez de recursos financeiros para preveni-los ou mitigá-los, o desafio de alocar fundos públicos não é uma tarefa trivial, sobretudo em Comitês de Bacias Hidrográficas, órgãos compostos por representantes com aspirações e interesses difusos, em torno do tema água. Motivado por esse desafio, este artigo tem objetivo de demonstrar como os critérios de investimentos, estabelecidos pelos comitês, podem ser utilizados como indutores da gestão integrada de recursos hídricos. Para tanto, foi realizada uma aplicação prática no Comitê da Bacia Hidrográfica do Alto Tietê (CBH-AT), durante atualização da Deliberação CBH-AT nº. 64/2018. Como resultados, foram elaborados critérios de rejeição e de avaliação, utilizados pelo $\mathrm{CBH}-\mathrm{AT}$ para selecionar os empreendimentos que receberam recursos públicos do Fundo Estadual de Recursos Hídricos (FEHIDRO), em 2019.

Palavras-chave: Gestão Integrada de Recursos Hídricos. Comitês de Bacias Hidrográficas. Apoio Multicritério à Decisão. Decisores.

\section{Abstract}

Considering the increase in water resources environmental impact and financial restrictions to prevent or mitigate them, the challenge to allocate public funds is impressive. The process is even harder in River Basin Committees composed by members with a variety of interests and aspirations regarding water theme. To address that, this paper aims to demonstrate how the investments criteria, established by the committees, can be used as integrated water resources management inductors. Therefore, a concrete implementation was done at the Alto Tietê River Basin Committee (CBH-AT), during the update of the Deliberation “ $C B H-A T n^{\circ}$. 64/2018”. As results, evaluation and rejection criteria were elaborated, that were used by the $C B H-A T$ to select the projects that have received public funds, in 2019, from the São Paulo State Water Resources Fund (FEHIDRO).

Keywords: Integrated Water Resources Management. River Basin Committees. Multiple Criteria Decision Aiding. Decision Maker.

\footnotetext{
${ }^{1}$ Agência Reguladora de Saneamento e Energia do estado de São Paulo (Arsesp) - São Paulo - São Paulo - Brasil.

${ }^{2}$ Universidade Estadual de Campinas - Campinas - São Paulo - Brasil.

* Autor correspondente: marcos.sartoriahotmail.com.
} 


\section{INTRODUÇÃO}

Os princípios da Conferência Internacional da Organização das Nações Unidas (ONU) sobre Água e Meio Ambiente, realizada em 1992, em Dublin na Irlanda, estabeleceram as bases contemporâneas da gestão integrada de recursos hídricos.

A gestão integrada dos recursos hídricos, segundo a Global Water Partnership (2000), representa "o processo que promove o desenvolvimento coordenado e o gerenciamento da água, terra e recursos relacionados, com finalidade de maximizar o bem-estar econômico e social de forma equitativa, sem comprometer a sustentabilidade dos ecossistemas vitais" (GWP, 2000, tradução nossa).

Conforme o Plano Estadual de Recursos Hídricos de São Paulo (PERH 2005), o Estado tomou a iniciativa e, antes mesmo da Conferência de Dublin, promulgou a Lei n ${ }^{0} .7 .663$ em 1991, que estabeleceu as normas de orientação à Política Estadual de Recursos Hídricos. Essa norma marcou o início da modernização da gestão de águas no Brasil.

Em 1997, foi sancionada a Lei $n^{\circ} .9 .433$, que instituiu a Política Nacional de Recursos Hídricos. Dentre os principais fundamentos da política destacam-se: a adoção da bacia hidrográfica como a unidade territorial de planejamento e a recomendação de que a gestão devia ser descentralizada e integrada, ao contar com a participação do poder público, dos usuários e das comunidades.

O gerenciamento de recursos hídricos é realizado por meio dos Comitês de Bacias Hidrográficas $(\mathrm{CBH})$, ou seja, órgãos colegiados, estratégicos, democráticos, participativos, de atuação descentralizada, compostos por representantes de diferentes segmentos de uma bacia. Nele ocorre a articulação entre o poder público, usuários e sociedade civil, visando formular o Plano de Bacia e indicar programas e projetos para preservar e recuperar os recursos hídricos (ANA, 2009).
Ainda tratando da Lei $n^{\circ} .9 .433 / 1997$, foram definidos 05 instrumentos de gestão, são eles: os Planos de Recursos Hídricos; o Enquadramento dos Corpos de Água em Classes; a Outorga de Direito de Uso de Recursos Hídricos; a Cobrança pelo Uso de Recursos Hídricos e o Sistema de Informações sobre Recursos Hídricos.

Os planos são desenvolvidos nas esferas nacional, estadual e de bacia hidrográfica. Tratando da escala da bacia, é o documento responsável, dentre outros temas, por traçar as diretrizes e orientar quais são os programas, projetos e ações necessárias à bacia. Logo, é fundamental que um plano possua um programa detalhado de investimentos.

Os recursos financeiros para os investimentos necessários são oriundos principalmente da cobrança pelo uso da água dos usuários outorgados, como também da compensação financeira, paga pela União aos Estados da Federação, em decorrência de inundações de áreas por reservatórios de água, para geração de energia hidroelétrica.

Neste sentido, os fundos de recursos hídricos ganham bastante significância, já que esses se multiplicam pelo país, à medida que ocorre a implementação da cobrança pelo uso da água nas bacias hidrográficas. Em consonância com Guimarães et al. (2008), os fundos estaduais de recursos hídricos emergem, portanto, como importante instituição do Sistema Nacional de Recursos Hídricos, possibilitando a viabilidade econômica e a possibilidade de uma efetiva descentralização do sistema de gestão.

É válido afirmar que os comitês são os espaços decisórios, no âmbito das bacias hidrográficas, que dentre suas atribuições, detêm o poder de decisão da escolha dos programas, projetos, serviços e obras, denominados neste artigo como empreendimentos, que receberão recursos financeiros dos fundos de recursos hídricos, e/ou dos recursos provenientes da cobrança pelo uso da água. 
A pesquisa justifica-se pela atual e futura importância dos investimentos a serem realizados nas bacias hidrográficas, sobretudo em função da crescente implementação da cobrança pelo uso da água, e consequente tendência de aumento dos recursos financeiros, ainda que escassos.

Utilizou-se como pergunta norteadora da pesquisa: como os critérios de investimentos, estabelecidos pelos comitês, podem induzir a gestão integrada de recursos hídricos?

Partiu-se da hipótese que, ao estabelecer ações ou projetos prioritários à bacia, sejam eles definidos pelo plano de bacia, relatório de situação ou mesmo pela preferência dos decisores, há a indução. Indução essa que não possui caráter negativo, pelo contrário, orienta as ações que são realmente necessárias à bacia hidrográfica.

Nos dois itens a seguir, é apresentada fundamentação teórica contendo as bases conceituais e metodológicas advindas, respectivamente, da disciplina de Gestão de Recursos Hídricos e da Metodologia Multicritério de Apoio à Decisão.

\subsection{Gestão de Recursos Hídricos}

A Declaração de Dublin merece atenção, pois estabeleceu as bases contemporâneas da gestão integrada de recursos hídricos. Dentre seus princípios, destaca-se o $2^{\circ}$ : "O desenvolvimento e a gestão da água devem ser baseados na participação de todos, envolvendo usuários, planejadores e decisores políticos, de todos os níveis." (DUBLIN, 1992, tradução nossa).

Dentre as primeiras ações efetivas no caminho da modernização do setor, registrou-se a decisão do governo do Estado de São Paulo de encaminhar à Assembleia Legislativa, em 1990, Projeto de Lei que institui a Política Estadual de Recursos Hídricos [...]. Tal projeto, convertido em Lei em 1991, consolidou a participação da sociedade civil no processo decisório, criou a cobrança pelo uso da água, e determinou que os recursos daí advindos fossem administrados pelo Fundo Estadual de Recursos Hídricos (FEHIDRO), para utilização direta nos Comitês de Bacia. O FEHIDRO passou a se constituir em uma das mais importantes inovações do setor ao garantir recursos diretamente voltados ao sistema de recursos hídricos [...] (ANA, 2002).

Em 1993, já sob a égide do novo arranjo institucional, o Estado de São Paulo criou o Comitê das Bacias dos Rios Piracicaba, Capivari e Jundiaí (CBH-PCJ). Na sequência, entre 1993 e 1997, foram criados 20 Comitês de Bacias Hidrográficas no Estado, que se constituíram em Unidades de Gerenciamento de Recursos Hídricos (UGRHIs). A experiência dos comitês de São Paulo foi considerada inovadora, por se tratar de colegiados com ação efetivamente deliberativa. "É deles a responsabilidade pela aplicação dos recursos provenientes do FEHIDRO" (ANA, 2002).

Anos mais tarde, a Lei Federal $n^{\circ}$. 9.433/1997, também conhecida como "Lei das Águas", foi instituída em um momento histórico em que o processo de participação social estava presente. Além da Constituição Federal de 1988 e a Declaração de Dublin, os marcos referenciais que influenciaram sua concepção foram: o Capítulo 18 da Agenda 21, as contribuições do Banco Mundial, por meio da publicação "A Policy Paper on Water Resources Management (1993)”, a própria Política de Recursos Hídricos do Estado de São Paulo, entre outras. (SARTORI, 2013).

O Fundo Estadual de Recursos Hídricos (FEHIDRO) constitui um dos aparatos legais do sistema da gestão das águas do Estado de São Paulo. É o fundo destinado a dar suporte financeiro à Política Estadual de Recursos Hídricos, por meio de projetos, serviços, ações e obras na área de recursos hídricos, previstos nos Planos das Bacias Hidro- 
gráficas (PBHs) e no Plano Estadual de Recursos Hídricos (PERH).

O FEHIDRO foi instituído pelo Capítulo III da Lei Estadual $n^{\circ}$. 7.663/1991. É regulamentado pelo Decreto $n^{\circ} .48 .896 / 2004$. Ademais, há uma série de deliberações do Conselho de Orientação do FEHIDRO (COFEHIDRO) que dispõem sobre as diretrizes e regras de operação do fundo.

O PERH define uma série de Programas de Duração Continuada (PDCs) e Subprogramas de Duração Continuada (SubPDCs), que englobam os principais temas a serem abordados e financiados para a gestão, recuperação e proteção das bacias hidrográficas do Estado de São Paulo. A partir dos PDCs e SubPDCs, podem ser definidas as linhas temáticas que direcionarão as ações financiadas com recursos do FEHIDRO, para alcançar os resultados esperados pelos Comitês de Bacias Hidrográficas (adaptado de COFEHIDRO, 2015).

Para um empreendimento ser financiado pelo FEHIDRO, em teoria, esse deve simultaneamente ser enquadrado em pelo menos um dos PDCs ou SubPDCs do PERH, estar previsto no plano de bacia da UGRHI, cumprir as exigências estabelecidas no Manual de Procedimentos Operacionais (MPO do FEHIDRO) e ser indicado por um comitê de bacia, após uma chamada pública.

A seguir foram listadas de maneira resumida as principais linhas de financiamento do FEHIDRO, ou seja, os PDCs estabelecidos na Deliberação CRH n. 190/2016.

PDC 1. Bases Técnicas em Recursos Hídricos (BRH); PDC 2. Gerenciamento dos Recursos Hídricos (GRH);

PDC 3. Melhoria e Recuperação da Qualidade das Águas (MRQ);

PDC 4. Proteção dos Corpos d'Água (PCA);

PDC 5. Gestão da Demanda de Água (GDA);

PDC 6. Aproveitamento dos Recursos Hídricos (ARH);
PDC 7. Eventos Hidrológicos Extremos (EHE); e PDC 8. Capacitação e Comunicação Social (CCS).

São duas as principais fontes financeiras do FEHIDRO: a compensação pelos usos hidroenergéticos, também chamada de royalties, e a cobrança pelo uso da água.

$O$ artigo $3^{\circ}$ da Lei 13.360/2016 explicita que quem paga pela compensação são as concessionárias ou os autorizados para exploração de potencial hidráulico aos Estados, ao Distrito Federal e aos Municípios, em cujos territórios se localizarem instalações destinadas à produção de energia elétrica, ou que tenham áreas invadidas por águas dos respectivos reservatórios.

Já a cobrança pelo uso da água é um instrumento da Política Nacional de Recursos Hídricos, que incide apenas sobre aqueles usos sujeitos a outorga. A cobrança objetiva, além do reconhecimento da água como um bem econômico, o incentivo à racionalização do uso e à obtenção de recursos financeiros para o financiamento de ações previstas nos planos de recursos hídricos.

Segundo dados do Relatório de Atividades FEHIDRO (COFEHIDRO, 2009), em 2008, aproximadamente $82,4 \%$ das receitas do fundo eram originadas a partir da compensação financeira. Já com a implementação gradual da cobrança pelo uso dos recursos hídricos, a situação alterou-se significativamente. Conforme dados do Relatório de Atividades FEHIDRO (COFEHIDRO, 2018), em 2017, os recursos provenientes da compensação financeira eram de $R \$ 81.619 .694,43$ (43,0\%), enquanto os recursos provenientes da cobrança pelo uso da água totalizavam $\mathrm{R} \$ 108.308 .381,03$ (57,0\%). Ou seja, no Estado de São Paulo, a cobrança pelo uso da água já se constitui como a principal fonte do recurso financeiro para o setor de recursos hídricos.

As funções exercidas pelos CBHs são básicas para o funcionamento do Sistema Integrado de Ge- 
renciamento de Recursos Hídricos do Estado de São Paulo (SIGRH), pois são os órgãos decisores quanto à implantação dos Planos de Bacias. Com base nos planos, os comitês escolhem quais os empreendimentos merecem a aplicação dos recursos financeiros do FEHIDRO (adaptado de COFEHIDRO, 2015).

\subsection{Metodologia Multicritério de Apoio à Decisão}

O processo de tomada de decisão para alocar recursos financeiros não é uma tarefa trivial, sobretudo em um fórum de decisão que possui representantes com aspirações e interesses difusos, ou até mesmo conflitantes, em torno do tema água. $\mathrm{A}$ atividade de estruturar as decisões justas, transparentes e de melhor compromisso, considerando os aspectos econômicos, sociais, ambientais, políticos entre outros, sendo muitas vezes estes subjetivos, é uma atividade complexa. Portanto, merece ser estudada sob a perspectiva do Apoio à Decisão, utilizando uma metodologia multicritério.

Segundo Roy (1993) o Apoio à Decisão pode ser definido como:

Uma atividade de alguém que, de maneira científica, busca obter elementos de respostas às perguntas feitas por atores envolvidos em um processo de tomada de decisão (ROY, 1993, tradução nossa).

Conforme Brandalise (2004), "definitivamente, o julgamento intuitivo é inadequado para decisões complexas que envolvem o futuro de milhares de vidas". De acordo com Matzenauer (2003), "as metodologias mais utilizadas no procedimento de avaliação de alternativas para o planejamento de recursos hídricos são oriundas da Pesquisa Operacional clássica”, contudo esses métodos não são capazes de lidar com situações complexas. Neste contexto, observa-se um processo de reformulação dos métodos de avaliação de alternativas, na área de planejamento de recursos hídricos, e essa mudança parte da análise tradicional custo-benefício para análise multicriterial.

Uma metodologia de Apoio Multicritério à Decisão procura fazer com que o processo seja o mais neutro, objetivo, válido e transparente possível, sem pretender indicar aos decisores uma solução única e verdadeira (GOMES, 2011).

Dentre as metodologias multicriteriais, destacam-se aquelas que têm por objetivo aumentar o conhecimento dos decisores (estruturar os problemas) e apoiar a decisão, fornecendo sugestões e contribuições que possuem como bases os valores e ensejos dos atores envolvidos. Segundo SDM (2002), "os problemas relacionados ao gerenciamento dos recursos hídricos não são estruturados (ou mesmo parcialmente estruturados)", ou seja, não existem soluções prontas a serem resolvidas por meio de algoritmos predefinidos.

Keeney afirma que "o pensamento focado no valor pode melhorar significativamente a tomada de decisão, pois os valores orientam não somente a criação de melhores alternativas, mas a identificação de melhores situações de decisão" (KEENEY, 1992, tradução nossa). Segundo o mesmo autor, apesar da maioria das tomadas de decisão ser focada, sobretudo nas escolhas entre alternativas, os valores dos decisores são mais fundamentais para um problema de decisão do que as próprias alternativas.

$\mathrm{Na}$ análise decisória não se objetiva avaliar os valores ou os julgamentos de indivíduos, mas sim fornecer subsídios para que os decisores possam de maneira consciente tomar as decisões consideradas mais adequadas, conforme os seus sistemas de valores.

Julgamentos pessoais sobre incerteza e valores são inputs importantes para a análise de decisão [...] eles são ingredientes importantes para tomar boas decisões [...]. 0 espírito da discussão é compreender os problemas que as pessoas 
enfrentam e aplicar cuidadosamente as técnicas de análise de decisão [...] (CLEMEN, 1996, tradução nossa).

Segundo Gomes (2009), os métodos de Apoio Multicritério procuram esclarecer o processo de decisão, tentando incorporar os julgamentos de valores dos agentes, na intenção de acompanhar a maneira como se desenvolvem as preferências e entendendo o processo como aprendizagem. Em consonância com Roy (1996, tradução nossa), "o apoio à decisão destina-se a auxiliar na construção, estabelecimento e defesa de convicções [...]".

Tomar decisões complexas é, de modo geral, uma das mais difíceis tarefas enfrentadas por indivíduos isolados ou mesmo por grupos. Quase sempre, tais decisões devem atender a múltiplos objetivos; são influenciadas por vários critérios, às vezes conflitantes, e sob muitos atributos; e seus impactos nem sempre podem ser bem identificados, principalmente ao longo do tempo (GOMES e GOMES, 2014).

Gomes (2009) cita um exemplo que elucida a diferença entre um critério e um atributo:

"Na escolha entre diversas marcas de um determinado produto, características como preço, qualidade, estética e durabilidade, por exemplo, devem ser consideradas pelo consumidor. Essas características são denominadas atributos. Quando a esses atributos acrescenta-se um mínimo de informação relativa às preferências desse consumidor, eles se convertem em critérios".

Analogamente, em um Comitê de Bacias Hidrográficas $(\mathrm{CBH})$, entre as diversas alternativas de potenciais empreendimentos a serem financiados, atributos como: valor do projeto, tempo de duração, valor da contrapartida, entre outros, podem ser considerados pelos representantes do comitê. Quando esses decisores se reúnem e entram em um consenso sobre suas preferências em relação aos atributos, estes se convertem em critérios.

\section{OBJETIVOS}

O objetivo da pesquisa concentrou-se em demonstrar como os critérios de investimentos, estabelecidos pelo Comitê da Bacia Hidrográfica do Alto Tietê (CBH-AT), podem ser utilizados como indutores da gestão integrada de recursos hídricos.

\section{METODOLOGIA}

Foi realizada a aplicação prática de alguns critérios indutores da gestão integrada de recursos hídricos, no CBH-AT, durante a atualização da Deliberação do CBH-AT n. 64 de 13 de dezembro de 2018, que aprovou os critérios de análise e hierarquização de empreendimentos para as indicações ao FEHIDRO, em 2019. A aplicação prática foi descrita em quatro etapas, as quais se basearam nos princípios da Metodologia Multicritério de Apoio à Decisão. A principal referência utilizada foi a obra: "Apoio à decisão: Metodologia para Estruturação de Problemas e Avaliação de Alternativas" de Ensslin, Montibeller e Noronha, de 2001.

\section{RESULTADOS E DISCUSSÃO}

\section{1 $1^{\text {a }}$ etapa) Identificação do Contexto}

Decisório. Objetivo: definir os decisores e o facilitador.

No dia $30 / 10 / 2018$, foi realizada a $13^{a}$ reunião da Câmara Técnica de Gestão de Investimentos (CTGI), do Comitê da Bacia Hidrográfica do Alto Tietê ( $\mathrm{CBH}-\mathrm{AT}$ ), que deu início às discussões sobre as atualizações dos critérios de investimentos para o ano de 2019.

A CTGI é composta por representantes (decisores) do $\mathrm{CBH}-\mathrm{AT}$, de maneira proporcional entre os segmentos que o compõe. São 05 votos para o Estado, 05 votos para a Sociedade Civil e 05 votos para os Municípios, conforme a Deliberação CBH-AT $n^{\circ} .37$ de 30 de março de 2017. A câma- 
ra possui como principais atribuições o estudo, avaliação e manifestação sobre a aplicação de recursos financeiros, oriundos da compensação financeira por aproveitamentos hidroenergéticos e da cobrança pelo uso dos recursos hídricos, na bacia do Alto Tietê.

Durante a reunião, o pesquisador realizou apresentação da "proposta de método para elaboração de critérios de investimentos a ser utilizado em comitês de bacias hidrográficas", e ao final da mesma, o coordenador da CTGI sugeriu que o pesquisador acompanhasse as próximas reuniões, na função de facilitador, com o objetivo de colocar em prática o método sugerido e contribuir com o aperfeiçoamento dos critérios existentes.

\section{2. $2^{\text {a }}$ etapa) Estruturação do problema. Objetivo: estruturar árvores de Pontos de Vista Fundamentais, conforme os valores dos decisores.}

No dia 08/11/2018, foi realizada a $14^{\text {a }}$ reunião da CTGI, em que o grupo de decisores concentrou-se em editar os artigos da minuta de deliberação, a partir da deliberação do ano anterior (CBH-AT nº. 50/2017).

Durante a reunião, o facilitador questionou o grupo de decisores com as seguintes perguntas: "Quais critérios vocês gostariam de levar em consideração?" e "Quais critérios de seleção contribuiriam para diminuir as dificuldades encontradas no processo de escolha das propostas nos anos anteriores?". Por meio das respostas obtidas, foi possível extrair alguns candidatos a Pontos de Vista Fundamentais (PVFs), descritos a seguir.

Ficou evidente a preocupação dos decisores em seguir as regras estabelecidas no Artigo $2^{\circ}$ da Deliberação CRH ad referendum nº. 188/2016, em que:
Artigo $2^{\circ}$ - $O$ "Plano de Ação para Gestão dos Recursos Hídricos da UGRHI" e o respectivo "Programa de Investimentos", para execução a partir de 2017, deverão estar estruturados conforme os Programas de Duração Continuada - PDC e deverão especificar as prioridades para investimentos de porcentagens da estimativa de receitas do Fundo Estadual de Recursos Hídricos - FEHIDRO referente ao $\mathrm{CBH}$, conforme segue:

Investimento de no máximo $25 \%$ (vinte e cinco por cento) nos "PDC 1 - Bases Técnicas em Recursos Hídricos - BRH" e "PDC 2 - Gerenciamento dos Recursos Hídricos - GRH”;

Investimento de no mínimo 60\% (sessenta por cento) em até 3 (três) PDCs, distribuídos em no máximo 6 (seis) Subprogramas de Duração Continuada (subPDC), a critério do CBH;

Investimento de no máximo $15 \%$ (quinze por cento) nas demais ações do Plano de Bacias (PBH), em PDCs a critério do CBH.

$\S 1^{\circ}$ - A priorização de PDCs e subPDCs citada no caput deve considerar a identificação e a análise de áreas críticas e a prioridade de ações para gestão dos recursos hídricos, constantes no Diagnóstico e do Prognóstico do PBH; [...]

Também se destacou a proposição de empreendimentos não alinhados com as necessidades reais da bacia, relatada como o principal problema encontrado pelos decisores, durante a avaliação de propostas nos anos anteriores. A partir desse consenso, foi possível identificar o problema do grupo de decisores: "Elaborar critérios de investimentos alinhados às necessidades da bacia".

Após a reunião, os candidatos a PVFs foram organizados em uma estrutura arborescente e agrupados em clusters pelo facilitador. 0 resultado pode ser observado na Fig. 1. 


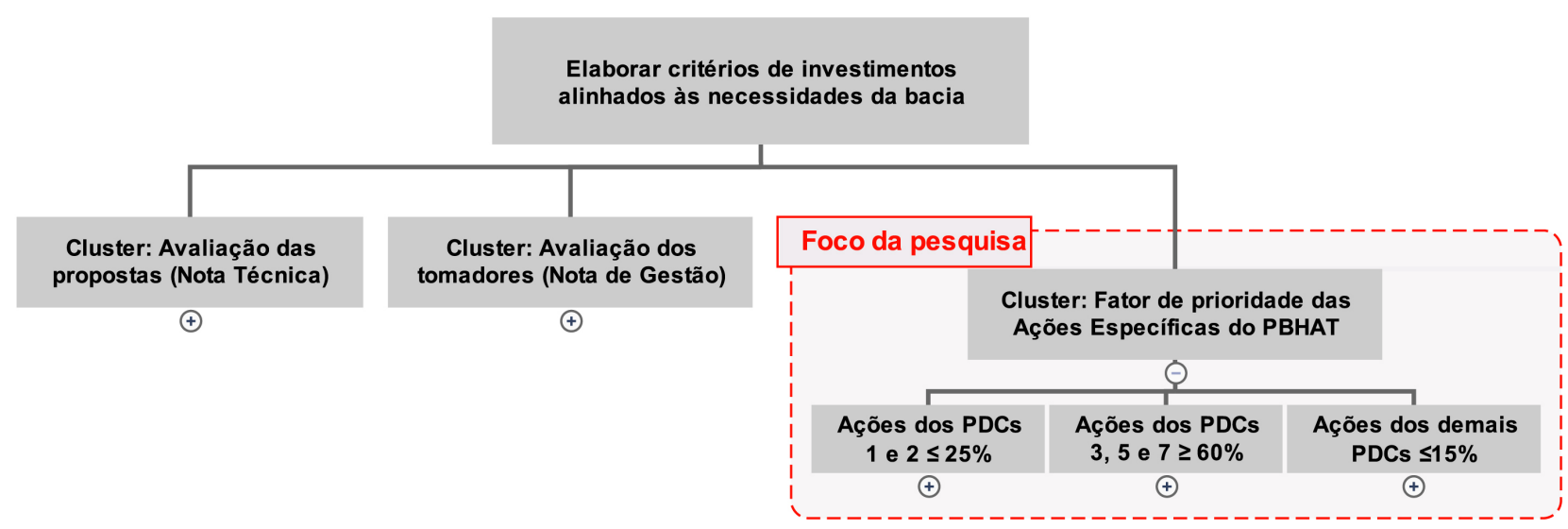

Figura 1. Árvore de PVFs

Ficou claro que os decisores não desejavam alterar profundamente a forma de pontuar os empreendimentos, utilizada nas deliberações de anos anteriores. Ou seja, estavam dispostos a manter a Nota Técnica (conjunto de critérios que avaliam a qualidade das propostas) e a Nota de Gestão (conjunto de critérios que avaliam a capacidade dos tomadores). Contudo, buscavam uma forma de indicar apenas as ações consideradas prioritárias, pelo Plano de Ação e Programa de Investimentos do Plano da Bacia. Notou-se também que, dentre as ações priorizadas pelo plano, os decisores consideravam a existência de níveis de preferências distintos, as mais prioritárias e as menos prioritárias para a bacia.

Logo, propôs-se o cluster o "Fator de prioridade das Ações específicas do Plano da Bacia Hidro- gráfica do Alto Tietê (PBHAT)”, para os três PVFs identificados e ratificados pelas regras estabelecidas no Artigo $2^{\circ}$ da Deliberação $\mathrm{CRH} \mathrm{n}^{\circ}$. $188 / 2016$.

4.3. $3^{\text {a }}$ etapa) Construção de critérios. Objetivo: construir os critérios de rejeição e os de avaliação

No dia $14 / 11 / 2018$, foi realizada a $15^{\text {a }}$ reunião da CTGI. Inicialmente, os decisores optaram por listar as ações de que a bacia necessitava para o ano de 2019, baseando-se nas informações contidas no Plano da Bacia e respeitando as regras estabelecidas na Deliberação CRH nº. 188/2016. A listagem foi resumida nas Tabelas 1, 2 e 3:

Tabela 1. Ações dos PDCs 1 e 2 passíveis de investimento (máximo de 25\%)

\begin{tabular}{|c|c|}
\hline Ação & SubPDC \\
\hline Aprimoramento e ampliação das redes de monitoramento de quantidade e qualidade das águas superficiais da BAT. & 1.4 \\
\hline $\begin{array}{l}\text { Estudo de viabilidade técnica, econômica e ambiental de implementação de sistemas de captação de vazões de tempo seco - } \\
\text { encaminhamento, em tempo seco, das vazões da rede de drenagem às ETEs. }\end{array}$ & 1.7 \\
\hline $\begin{array}{l}\text { Incentivo ao cadastro/outorga para usuários de recursos hídricos não cadastrados/ outorgados, regularização dos usuários, e } \\
\text { manutenção de banco de dados atualizado e completo. }\end{array}$ & 2.2 \\
\hline
\end{tabular}


Tabela 2. Ações dos PDCs 3, 5 e 7 passíveis de investimento (mínimo de 60\%)

\begin{tabular}{|c|c|}
\hline Ação & SubPDC \\
\hline Execução de projetos e obras para implantação de sistemas de coleta, transporte e tratamento de esgotos nas áreas de mananciais. & 3.1 \\
\hline Aumento da capacidade de tratamento de esgotos para a universalização do serviço nas áreas de mananciais. & 3.1 \\
\hline $\begin{array}{l}\text { Execução de obras de saneamento básico (exceto rede de abastecimento de água) vinculadas à promoção da urbanização de } \\
\text { assentamentos precários de interesse social em áreas de mananciais. }\end{array}$ & $3.1 ; 3.2 ; 3.3$ \\
\hline $\begin{array}{c}\text { Execução de ações estruturais para redução de perdas no Sistema de Abastecimento Público, desde que previstas em Plano de Controle e } \\
\text { Redução de Perdas. }\end{array}$ & 5.1 \\
\hline Execução de projetos e obras estruturais previstas no PDMAT 3. & 7.2 \\
\hline
\end{tabular}

As ações das Tabelas 1 e 2 foram extraídas literalmente do "Resumo Executivo do Plano da Bacia do Alto Tietê", mais especificamente das
"Ações propostas para 2019", desde que possuíssem recursos previstos e fossem denominadas como "Imediatas" pelo plano.

Tabela 3. Demais ações passíveis de investimento (máximo 15\%)

\begin{tabular}{|c|c|}
\hline Ação & SubPDC \\
\hline Execução de projetos e obras para implantação de sistemas de coleta, transporte e tratamento de esgotos fora das áreas de mananciais. & 3.1 \\
\hline Aumento da capacidade de tratamento de esgotos para a universalização do serviço fora das áreas de mananciais. & 3.1 \\
\hline $\begin{array}{l}\text { Implantação de sistemas de tratamento de resíduos sólidos domiciliares (triagem, compostagem, transbordo, logística reversa, } \\
\text { reciclagem), nos casos em que há comprometimento dos recursos hídricos. }\end{array}$ & 3.2 \\
\hline Projetos básico e executivo de obras para a recuperação ou renaturalização de corpos hídricos, principalmente em áreas de mananciais. & 3.5 \\
\hline $\begin{array}{l}\text { Estruturação e aplicação de sistemas integrados de fiscalização do uso do solo, em áreas de mananciais, por meio de parcerias entre o } \\
\text { Estado e os Municípios para aquisição e análise de imagens de satélite. }\end{array}$ & 4.1 \\
\hline Promoção de campanhas de conscientização da população quanto à necessidade de ligação à rede de esgotamento sanitário & 8.2 \\
\hline
\end{tabular}

Já as demais ações da Tabela 3 contam tanto com as "Ações propostas para 2019" (ações do SubPDC 3.1) como com as ações planejadas para o quadriênio 2020/2023, classificadas como de "Alta Prioridade" (ações dos SubPDCs 3.2, 3.5, 4.1 e 8.2), extraídas do "Relatório Parcial do Plano de Ação" (RPA), datado de 10/05/2018.

Ao definir três listagens contendo somente aquelas ações financiáveis, foi definido automaticamente um critério de rejeição. Ou seja, as propostas que não se enquadrem nas ações passíveis de investimentos serão eliminadas antes mesmo de serem avaliadas ou hierarquizadas.

O critério de rejeição resolveu parcialmente o problema dos decisores, já que ainda existia a percepção dos decisores quanto à diferença de prioridade entre ações listadas nos quadros. Logo, foi necessária a criação de critérios de avaliação, sob a luz da Problemática da Ordenação (P. $\gamma$ ). Problemática que tem como objetivo hierarquizar as alternativas levando em conta uma ordem de preferência decrescente, um ranking de alternativas (empreendimentos), tendo como base as preferências dos decisores.

Assim, a árvore de PVFs (Fig. 1) foi submetida à avaliação dos decisores. Após o consenso, foi solicitada a inclusão das ações passíveis de investimentos sob os PVFs, conforme Fig.2. $\mathrm{Na}$ sequência, a árvore foi validada pelos decisores. 


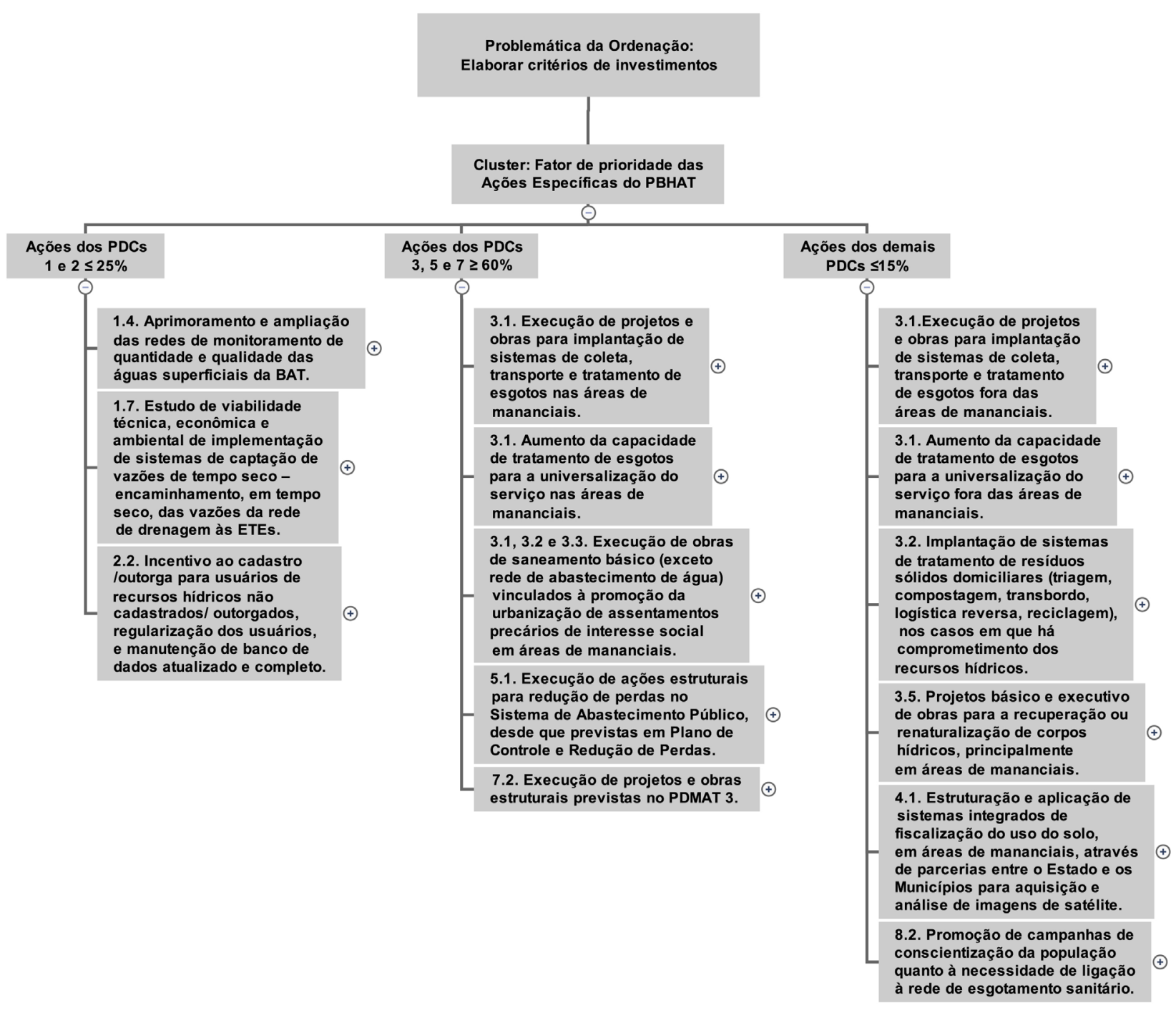

Figura 2. Árvore de PVFs validada pelos decisores

As ações passíveis de investimentos incluídas na árvore foram consideradas como descritores, isto é, um "conjunto de níveis de impacto que servem como base para descrever as performances plausíveis das ações potenciais" (BANA e COSTA, 1992, et al., 1999).
$\mathrm{Na}$ sequência, os decisores atribuíram valores para cada nível de impacto dos descritores, por meio de comparações relativas, sempre em relação ao melhor nível de impacto possível. A diferença de atratividade ou de predileção entre os níveis de impacto de um descritor é denominada função de valor (Fig. 3). 


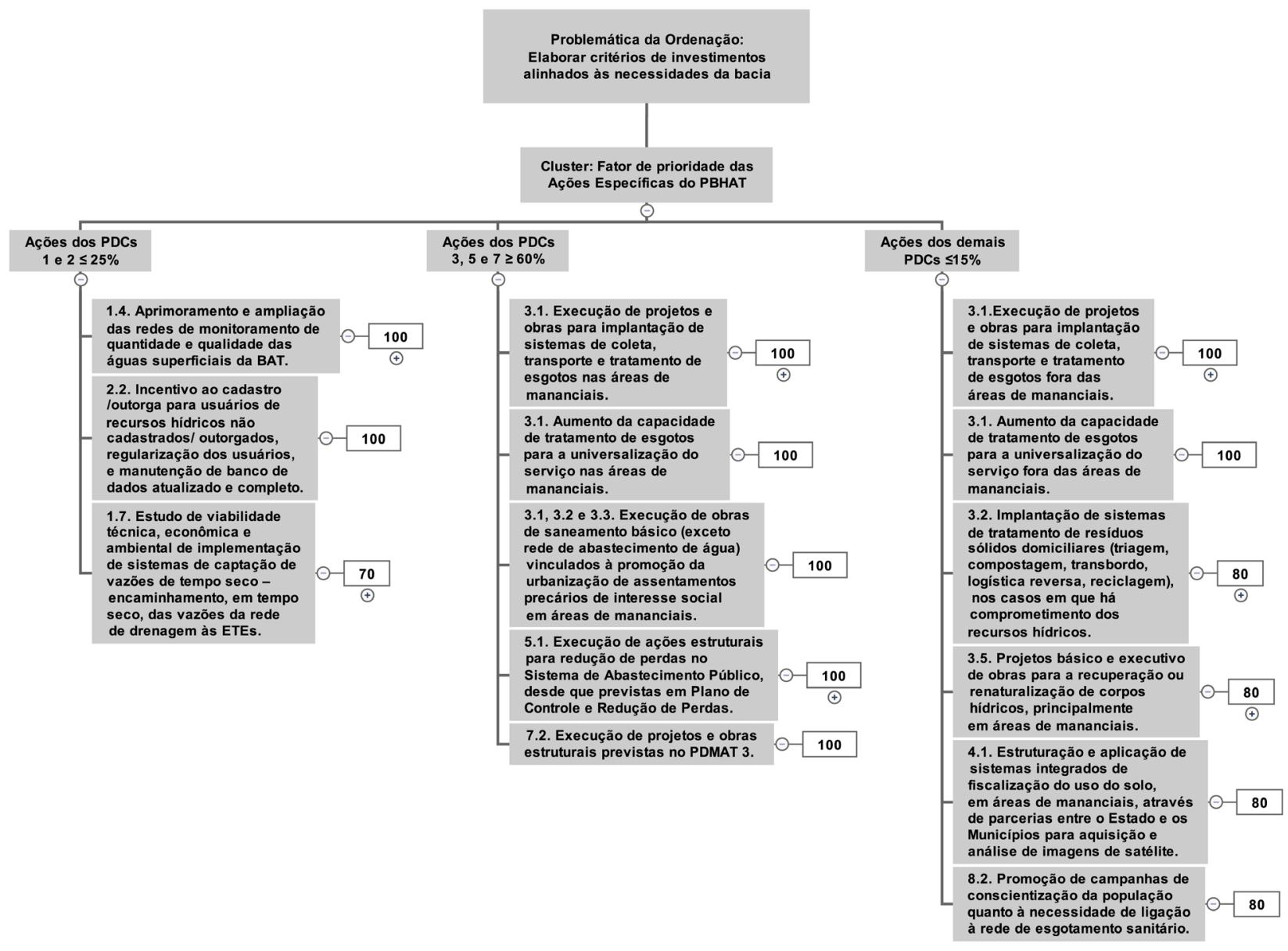

Figura 3. Funções de valor

A diferença de atratividade entre os níveis de impacto foi definida pelo consenso dos decisores, de acordo com os seus sistemas de valores. No entanto, foram observados alguns padrões nas pontuações, conforme a lógica descrita a seguir:

- As ações imediatas do plano, planejadas para 2019, têm prioridade sobre as ações de curto prazo com prioridade alta, planejadas para o quadriênio 2020-2023. Visto que as ações de curto prazo obtiveram pontuação 80 ; e

- As ações previstas com recursos do FEHIDRO têm prioridade sobre as ações setoriais (que possuem orçamento próprio e podem contar eventualmente com recursos do FEHIDRO). Visto que a única ação setorial (1.7) obteve pontuação 70.
A partir da construção das funções de valor, os PVFs passaram a ser efetivamente chamados de critérios de avaliação. Dentre as principais características dos critérios de avaliação, destaca-se que esses se enquadram na Problemática da Ordenação e são caracterizados por serem condicionais, isto é, uma proposta de empreendimento poderá ser classificada somente em um dos critérios. Logo, existirão três rankings distintos de empreendimentos após as avaliações das alternativas, um para cada critério de avaliação condicional.

A não necessidade de criação de taxas de substituição (estabelecimento de pesos dos critérios) fica clara ao perceber que já existe uma diferenciação entre os critérios condicionais, quando se estipulam porcentagens máximas e mínimas de recursos que serão investidas em cada PDC. 
4.4. $4^{\mathrm{a}}$ etapa) Revisão das funções de valor . Objetivo: ratificar as funções de valor

No dia $28 / 11 / 2018$ foi realizada a $16^{\text {a }}$ reunião da CTGI. Motivados por estabelecer diferenciações entre os níveis de impacto dos descritores, os decisores refinaram as funções de valor dos critérios estabelecidos. A Fig. 4 resume de forma gráfica os aprimoramentos.

As ações 1.4, 1.7, 3.2 e 3.5 foram segmentadas em duas subações: as dentro de Áreas de Proteção aos Mananciais (APM) e Área de Proteção e Recuperação dos Mananciais (APRM) e as fora de APM/APRM, de maneira que as proposituras situadas dentro dessas áreas têm prioridade sobre as situadas fora.

As ações relacionadas ao esgoto, contidas no 3.1, também foram segmentadas em duas subações: em municípios com Índice de Atendimento de Urbano de Esgoto (ICE') menor que 70\% e em municípios com ICE maior ou igual a 70\%, de maneira que as proposituras situadas em municípios com ICE menor que $70 \%$, têm prioridade sobre as demais.

Já as ações relacionadas às perdas de água foram segmentadas em três subações: em municípios com Índice de Perdas na Distribuição (IPD²) maior ou igual a $40 \%$; IPD menor que $40 \%$ e maior que $25 \%$; e IPD menor ou igual a $25 \%$ e maior ou igual a 5\%; de maneira que as proposituras situadas em municípios com maiores perdas têm prioridade sobre as demais.

Convencionou-se que, caso as ações descritas nos últimos dois parágrafos sejam propostas para setores de esgotamento ou abastecimento que tenham abrangência de mais de um município, considerar-se-á o valor do ICE ou IPD mais favorável à hierarquização da proposta.

O resultado da multiplicação, do valor atribuído à subação pelo valor atribuído à ação, foi denominado Fator de Prioridade (K). Fator este que foi acrescentado à fórmula utilizada para avaliação e hierarquização das propostas de empreendimentos recebidas pelo comitê, descrita a seguir.

$N F=(N T+N G) \times K$

Em que:

NF = Nota Final para hierarquização dos empreendimentos;

NT = Nota Técnica, obtida pela somatória das notas NT1 + NT2 + NT3 + NT4 + NT5;

$N G=$ Nota de Gestão, obtida pela somatória das notas NG1 + NG2 + NG3;

$\mathrm{K}=$ Fator de Prioridade de acordo com as Tabelas 04, 05 e 06.

\footnotetext{
1 Disponível no SNIS (2015) e no Resumo Executivo do PBHAT (2018-2045).

${ }^{2}$ Disponível no SNIS (2015) e no Resumo Executivo do PBHAT (2018-2045), em que o IPD $\geq 40 \%$ é Ruim; >25\% e <40\% é Regular; $\geq 5 \%$ e $\leq 25 \%$ é Bom.
} 


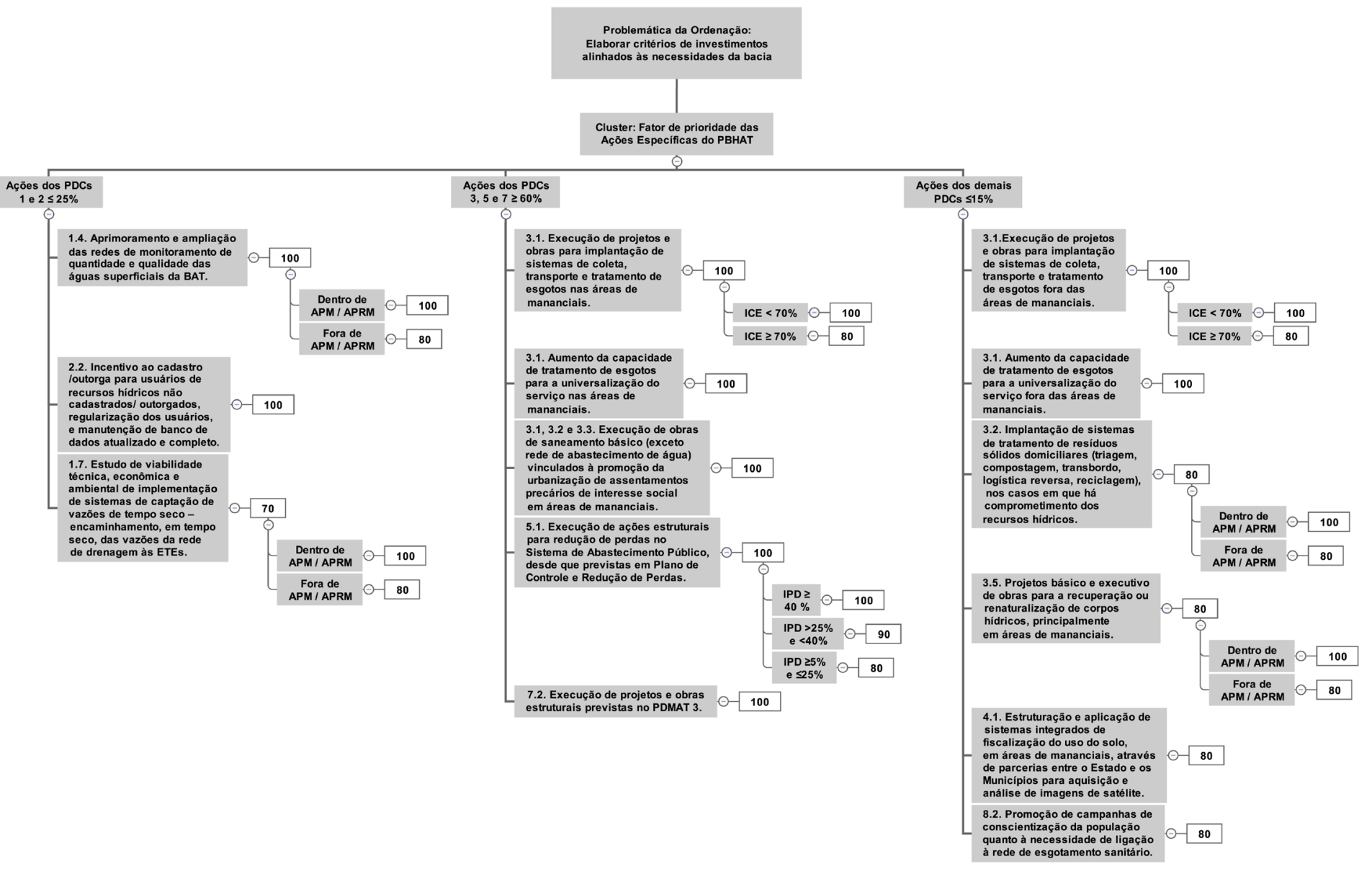

Figura 4. Funções de valor aprimoradas

Os critérios utilizados para o cálculo da Nota Técnica e da Nota de Gestão não foram o foco desta pesquisa e podem ser observados na Deliberação CBH-AT n. 64/2018, publicada no Diário Oficial do Estado de São Paulo, em 22 de dezembro de 2018. Já o Fator de Prioridade K, contribuição deste trabalho, é detalhado no item 5 deste artigo, "Discussão".

Tabela 4. Fator K das ações e subações dos PDCs 1 e 2 (máximo de 25\%)

\begin{tabular}{|c|l|c|}
$\begin{array}{c}\text { Sub } \\
\text { PDC }\end{array}$ & \multicolumn{1}{c|}{$\begin{array}{c}\text { Fator de } \\
\text { Ação } \\
\text { Prioridade (K) }\end{array}$} \\
\hline $\mathbf{1 . 4}$ & $\begin{array}{l}\text { Aprimoramento e ampliação das redes de monitoramento de quantidade e qualidade das águas superficiais da BAT - Dentro } \\
\text { de APM / APRM. }\end{array}$ & 1,00 \\
\hline $\mathbf{1 . 4}$ & $\begin{array}{l}\text { Aprimoramento e ampliação das redes de monitoramento de quantidade e qualidade das águas superficiais da BAT - Fora de } \\
\text { APM / APRM. }\end{array}$ & 0,80 \\
\hline $\mathbf{1 . 7}$ & $\begin{array}{l}\text { Estudo de viabilidade técnica, econômica e ambiental de implementação de sistemas de captação de vazões de tempo seco - } \\
\text { encaminhamento, em tempo seco, das vazões da rede de drenagem às ETEs - Dentro de APM / APRM. }\end{array}$ & 0,70 \\
\hline $\mathbf{1 . 7}$ & $\begin{array}{l}\text { Estudo de viabilidade técnica, econômica e ambiental de implementação de sistemas de captação de vazões de tempo seco - } \\
\text { encaminhamento, em tempo seco, das vazões da rede de drenagem às ETEs - FFora de APM / APRM. }\end{array}$ & 0,56 \\
\hline $\mathbf{2 . 2}$ & $\begin{array}{l}\text { Incentivo ao cadastro/outorga para usuários de recursos hídricos não cadastrados/outorgados, regularização dos usuários e } \\
\text { manutenção de banco de dados atualizado e completo. }\end{array}$ & 1,00 \\
\hline
\end{tabular}


Tabela 5: Fator K das ações e subações dos PDCs 3, 5 e 7 (mínimo de 60\%)

\begin{tabular}{|c|c|c|}
\hline $\begin{array}{l}\text { Sub } \\
\text { PDC }\end{array}$ & Ação & $\begin{array}{l}\text { Fator de } \\
\text { Prioridade (K) }\end{array}$ \\
\hline 3.1 & $\begin{array}{l}\text { Execução de projetos e obras para implantação de sistemas de coleta, transporte e tratamento de esgotos nas áreas de } \\
\text { mananciais - Em município com ICE < 70\%. }\end{array}$ & 1,00 \\
\hline 3.1 & $\begin{array}{l}\text { Execução de projetos e obras para implantação de sistemas de coleta, transporte e tratamento de esgotos nas áreas de } \\
\text { mananciais - Em município com ICE } \geq 70 \% \text {. }\end{array}$ & 0,80 \\
\hline 3.1 & Aumento da capacidade de tratamento de esgotos para a universalização do serviço nas áreas de mananciais. & 1,00 \\
\hline $\begin{array}{l}\text { 3.1, } 3.2 \mathrm{e} \\
\text { 3.3. }\end{array}$ & $\begin{array}{l}\text { Execução de obras de saneamento básico (exceto rede de abastecimento de água) vinculadas à promoção da urbanização de } \\
\text { assentamentos precários de interesse social em áreas de mananciais. }\end{array}$ & 1,00 \\
\hline 5.1. & $\begin{array}{l}\text { Execução de ações estruturais para redução de perdas no Sistema de Abastecimento Público, desde que previstas em Plano } \\
\text { de Controle e Redução de Perdas - Em município com IPD } \geq \mathbf{4 0 \%} \text {. }\end{array}$ & 1,00 \\
\hline 5.1 & $\begin{array}{l}\text { Execução de açães estruturais para redução de perdas no Sistema de Abastecimento Público, desde que previstas em Plano } \\
\text { de Controle e Redução de Perdas - Em município com IPD }>\mathbf{2 5 \%} \text { e }<\mathbf{4 0 \%} \text {. }\end{array}$ & 0,90 \\
\hline 5.1 & $\begin{array}{l}\text { Execução de ações estruturais para redução de perdas no Sistema de Abastecimento Público, desde que previstas em Plano } \\
\text { de Controle e Redução de Perdas - Em município com IPD } \geq 5 \% \text { e } \leq \mathbf{2 5 \%} \text {. }\end{array}$ & 0,80 \\
\hline 7.2 & Execução de projetos e obras estruturais previstas no PDMAT 3. & 1,00 \\
\hline
\end{tabular}

Tabela 6: Fator $K$ das demais ações e subações (máximo 15\%)

\begin{tabular}{|c|c|c|}
\hline $\begin{array}{l}\text { Sub } \\
\text { PDC }\end{array}$ & Ação & $\begin{array}{l}\text { Fator de } \\
\text { Prioridade (K) }\end{array}$ \\
\hline 3.1 & $\begin{array}{l}\text { Execução de projetos e obras para implantação de sistemas de coleta, transporte e tratamento de esgotos fora das áreas de } \\
\text { mananciais - Em município com ICE < } 70 \% \text {. }\end{array}$ & 1,00 \\
\hline 3.1 & $\begin{array}{l}\text { Execução de projetos e obras para implantação de sistemas de coleta, transporte e tratamento de esgotos fora das áreas de } \\
\text { mananciais - Em município com ICE } \geq 70 \% \text {. }\end{array}$ & 0,80 \\
\hline 3.1 & Aumento da capacidade de tratamento de esgotos para a universalização do serviço fora das áreas de mananciais. & 1,00 \\
\hline 3.2 & $\begin{array}{l}\text { Implantação de sistemas de tratamento de resíduos sólidos domiciliares (triagem, compostagem, transbordo, logística } \\
\text { reversa, reciclagem), nos casos em que há comprometimento dos recursos hídricos - Dentro de APM / APRM. }\end{array}$ & 0,80 \\
\hline 3.2 & $\begin{array}{l}\text { Implantação de sistemas de tratamento de resíduos sólidos domiciliares (triagem, compostagem, transbordo, logística } \\
\text { reversa, reciclagem), nos casos em que há comprometimento dos recursos hídricos - Fora de APM / APRM. }\end{array}$ & 0,64 \\
\hline 3.5 & $\begin{array}{l}\text { Projetos básico e executivo de obras para a recuperação ou renaturalização de corpos hídricos, principalmente em áreas de } \\
\text { mananciais - Dentro de APM / APRM. }\end{array}$ & 0,80 \\
\hline 3.5 & $\begin{array}{l}\text { Projetos básico e executivo de obras para a recuperação ou renaturalização de corpos hídricos, principalmente em áreas de } \\
\text { mananciais - Fora de APM / APRM. }\end{array}$ & 0,64 \\
\hline 4.1 & $\begin{array}{l}\text { Estruturação e aplicação de sistemas integrados de fiscalização do uso do solo, em áreas de mananciais, por meio de } \\
\text { parcerias entre o Estado e os Municípios para aquisição e análise de imagens de satélite. }\end{array}$ & 0,8 \\
\hline 8.2 & $\begin{array}{l}\text { Promoção de campanhas de conscientização da população quanto à necessidade de ligação à rede de } \\
\text { esgotamento sanitário. }\end{array}$ & 0,8 \\
\hline
\end{tabular}

\section{DISCUSSÃO}

$\mathrm{O}$ Fator de Prioridade $\mathrm{K}$ é um coeficiente adimensional que varia entre 0,56 e 1,00, em que as ações ou subações, classificadas com coeficientes maiores, têm maior probabilidade de serem financiadas do que as com os coeficientes menores. Funciona também como um fator limitante, pois uma proposta com $\mathrm{K}=1,00$ terá a possibilidade de atingir $100 \%$ da pontuação máxima, mas uma proposta com $\mathrm{K}=0,56$ estará limitada a $56 \%$ da pontuação máxima.

Cabe relembrar que, como os critérios de avaliação são condicionais, não haverá uma única lista de empreendimentos hierarquizados, mas sim três diferentes e não concorrentes, respeitando as porcentagens máximas e mínimas estabelecidas na Deliberação CRH 188/2016 e nos critérios estabelecidos pelos decisores. Logo, a hierarquização se resume à criação de três listas de empreendimentos, ordenados de forma decrescente, conforme as Notas Finais.

No dia 13/12/2018, a minuta da Deliberação CBH-AT n. 64/2018, contendo a contribuição deste trabalho (Fator de Prioridade K), foi submetida à avaliação durante a $9^{a}$ Reunião Plenária do Comitê da Bacia Hidrográfica do Alto Tietê. Antes de colocar o assunto em avaliação e votação, o coordenador da CTGI e o pesquisador 
apresentaram, respectivamente, a deliberação e os critérios criados. Após as manifestações dos presentes e inclusões e melhorias no texto da minuta, partiu-se para a votação pela aprovação ou rejeição da minuta. Foram contabilizados 17 votos a favor da aprovação e 01 voto pela rejeição da deliberação, ou seja, 94,44\% de aceitação.

Por conseguinte, a Deliberação CBH-AT $n^{\circ}$. $64 / 2018$, que aprovou os critérios para análise e hierarquização de empreendimentos, para indicação ao FEHIDRO em 2019, foi publicada no Diário Oficial do Estado de São Paulo, em 22/12/2018. Já no dia 03/01/2019, foi iniciado o prazo para a chamada pública para recebimento de propostas de empreendimentos.

Por fim, ao analisar criticamente os resultados deste artigo, pode-se afirmar que o Fator de Prioridade $\mathrm{K}$ tornou-se determinante para a escolha das propostas de empreendimentos a serem indicados pelo Comitê do Alto Tietê, pois proporciona o alinhamento às prioridades estabelecidas e apontadas pelo Plano da Bacia, em diferentes níveis de preferência, estabelecidos por decisores representativos.

\section{CONCLUSÕES}

Tendo como base a fundamentação teórica, foram elaborados critérios (de rejeição e de avaliação) utilizados pelo Comitê da Bacia Hidrográfica do Alto Tietê (CBH-AT) para selecionar aqueles empreendimentos, na área de recursos hídricos, que receberam recursos públicos do FEHIDRO, no ano de 2019.

Obtiveram-se como principais resultados: a definição do facilitador e dos decisores, estruturação do problema em forma gráfica, definição de critérios de rejeição e de avaliação. Esses últimos dotados de função de valor, representada pelo Fator de Prioridade (K).

O K é uma ferramenta de apoio à decisão ao principal problema relatado pelos decisores: "Elaborar critérios de investimentos alinhados às necessidades da bacia”. Ferramenta esta que foi aceita como útil e válida pelos decisores e compôs o modelo utilizado para selecionar as mais adequadas propostas de empreendimentos, para o ano de 2019, segundo o sistema de valores dos decisores. $\mathrm{Ou}$ seja, os critérios que já avaliavam o conteúdo das propostas e a capacidade da instituição proponente foram somados ao $\mathrm{Ke}$, juntos, contribuem para a seleção das propostas com os melhores conteúdos, melhores tomadores e prioritárias à bacia.

Quanto à pergunta norteadora da pesquisa: "Como os critérios de investimentos, estabelecidos pelos comitês, podem induzir a gestão integrada de recursos hídricos?", tem-se que os critérios criados não visam a indicar os empreendimentos considerados ótimos, tampouco representar uma realidade objetiva para tomar decisões, mas, sim, recomendar empreendimentos alinhados aos valores do grupo de decisores representativos, por meio de uma ferramenta válida para o processo de apoio à decisão, processo que pressupõe interações entre os decisores e gera conhecimento ao estruturar os problemas.

Pode-se afirmar também que os critérios de investimentos são muito específicos, em função das necessidades de desenvolvimento de cada região ou sub-região hidrográfica. Os representantes do comitê são os responsáveis por indicar aqueles empreendimentos que contemplem tais necessidades, sempre com o apoio das publicações oficiais estabelecidas em lei, como o Plano Estadual de Recursos Hídricos (PERH), os planos de bacias e os relatórios de situação. Tal fato corrobora a hipótese deste artigo. Ademais, aproxima-se de bons critérios indutores de investimentos quando os anseios dos representados são identificados, interpretados e atendidos pelo poder público, de forma dinâmica e contínua.

Esta pesquisa representa apenas uma pequena parcela de um amplo espectro de estudos possíveis 
sobre a elaboração de critérios de investimentos no âmbito dos $\mathrm{CBH}$. Assim, há a possibilidade de realização de mais estudos que subsidiem o apoio aos decisores. Como desafios para pesquisas futuras, almeja-se a aplicação do Apoio à Decisão em outros $\mathrm{CBHs}$, com finalidade de comparar os resultados obtidos, como também testar a validade e aplicabilidade das etapas desse método para elaboração dos programas de investimentos dos Planos de Bacias Hidrográficas.

\section{AGRADECIMENTOS}

Ao Conselho Nacional de Desenvolvimento Científico e Tecnológico (CNPq), processo 167570/2018-8º è Coordenação de Aperfeiçoamento de Pessoal de Nível Superior - Brasil (CAPES) - Código de Financiamento 001 (processo $05-P-04770-2018)$.

\section{CONTRIBUIÇÃO DOS AUTORES}

Todos os autores contribuíram de forma igualitária.

\section{REFERÊNCIAS}

ANA - AGÊNCIA NACIONAL DE ÁGUAS (Brasil). A Implementação da Cobrança pelo Uso de Recursos Hídricos e Agência de água das bacias dos Rios Piracicaba, Capivari e Jundiaí. - Brasília: ANA, SAG, ed. português/inglês, 2009.

ANA - AGÊNCIA NACIONAL DE ÁGUAS (Brasil). The Evolution of Water Resources Management in Brazil. Brasília, ANA, 2002.

BANA E COSTA, Carlos Antonio; ENSSLIN, Leonardo; CORRÊA, Émerson C.; VANSNICK, Jean-Claude. Decision Support Systems in Action: Integrated Application in a Multicriteria Decision Aid Process. European Journal of Operational Research, v.113, n. 2, p. 315 - 335, 1999. Disponível em: <https://doi.org/10.1016/ S0377-2217(98)00219-7> Acesso em: jan 2019.

BRANDALISE, Karla Cristina dos Anjos. Metodologia de apoio à decisão construtivista para aperfeiçoamento de processos de faturamento em uma organização. 2004. Dissertação (Mestrado em Engenharia de Produção). Universidade Federal de Santa Catarina, Florianópolis, 2004
BRASIL. Lei n. 9.433, de 08 de janeiro de 1997. Institui a Política Nacional de Recursos Hídricos, cria o Sistema Nacional de Gerenciamento de Recursos Hídricos [...] Disponível em: <http://www. ana.gov.br/Institucional/Legislacao/leis/lei9433.pdf>. Acesso: 22 ago 2015.

BRASIL. Lei $\mathbf{n}^{\circ}$. 13.360, de 17 de novembro de 2016. Altera a Lei n 5.655, de 20 de maio de 1971 [...] e dá outras providências. Disponível em: <http://www.planalto.gov.br/ccivil_03/_Ato20152018/2016/Lei/L13360.htm>. Acesso: 03 jan 2019.

CBH-AT. Comitê da Bacia Hidrográfica do Alto Tietê. Aprova critérios para análise e hierarquização de empreendimentos para indicação ao FEHIDRO em 2018, e dá outras providências. Deliberação CBH-AT $n^{\circ} .50$ de 14 de dezembro de 2017. Disponível em: <http://www.sigrh.sp.gov.br/cbhat/deliberacoes>. Acesso em: 22 jan 2018.

CBH-AT. Comitê da Bacia Hidrográfica do Alto Tietê. Aprova critérios para análise e hierarquização de empreendimentos para indicação ao FEHIDRO em 2019, e dá outras providências. Deliberação CBH-AT n ${ }^{\circ} .64$ de 13 de dezembro de 2018. Disponível em: <http://www.sigrh.sp.gov.br/cbhat/deliberacoes>. Acesso em: 03 jan 2019.

CBH-AT. Comitê da Bacia Hidrográfica do Alto Tietê. Elege a Diretoria, os representantes para as Câmaras Técnicas, o CRH, o CONESAN e os Conselhos Deliberativo e Fiscal da FABHAT, e dá outras providências. Deliberação CBH-AT $n^{\circ} .37$ de 30 de março de 2017. Disponível em: <http://www.sigrh.sp.gov.br/cbhat/deliberacoes>. Acesso em: 22 jan 2018.

CBH-AT. Comitê da Bacia Hidrográfica do Alto Tietê. Plano da Bacia Hidrográfica do Alto Tietê (PBH-AT) 2018-2045. Resumo executivo. São Paulo: Consórcio Cobrape / JNS, 2018.

CBH-AT. Comitê da Bacia Hidrográfica do Alto Tietê. Relatório Parcial do Plano de Ação (RPA). Elaboração do Plano da Bacia Hidrográfica do Alto Tietê. São Paulo: Consórcio Cobrape / JNS, 2018.

CLEMEN, Robert T. Making hard decisions: an introduction to decision analysis. $2^{\mathrm{a}}$ ed. Pacific Grove, Califórnia: Duxburg Press, 1996.

COFEHIDRO - CONSELHO DE ORIENTAÇÃO DO FUNDO ESTADUAL DE RECURSOS HÍDRICOS (São Paulo). Relatório de Atividades FEHIDRO: exercício de 2008. Secretaria de Energia, Recursos Hídricos e Saneamento. São Paulo, 2009. 45p. Disponível em: < http://www.sigrh.sp.gov.br/cofehidro/relatoriosanuaisdeatividades> Acesso em: 21 dez 2018.

COFEHIDRO - CONSELHO DE ORIENTAÇÃO DO FUNDO ESTADUAL DE RECURSOS HÍDRICOS (São Paulo). Relatório de Atividades FEHIDRO: exercício de 2017. Secretaria de Energia, Recursos Hídricos e Saneamento. São Paulo, 20018. 10p. Disponível em: < http://www.sigrh.sp.gov.br/cofehidro/relatoriosanuaisdeatividades> Acesso em: 21 dez 2018. 
COFEHIDRO - CONSELHO DE ORIENTAÇÃO DO FUNDO ESTADUAL DE RECURSOS HÍDRICOS (São Paulo). Manual de Procedimentos Operacionais para Investimento (MPO). Anexo II da deliberação COFEHIDRO nº 158/2015. São Paulo, 2015.

CRH. CONSELHO ESTADUAL DE RECURSOS HÍDRICOS (São Paulo). Estabelece o formato e o cronograma de entrega dos Planos de Bacias Hidrográficas - PBH e dá providências suplementares [...]. Deliberação CRH “Ad Referendum" n 188, de 09 de novembro de 2016. Disponível em: <http://www.sigrh.sp.gov.br/crh/deliberacoes>. Acesso em: 16 jan 2017.

ENSSLIN, Leonardo; MONTIBELLER, Gilberto; NORONHA, Sandro. Apoio à decisão: Metodologia para Estruturação de Problemas e Avaliação de Alternativas. Florianópolis: Insular, 2001.

FANTINATTI, Pedro Augusto Pinheiro; ZUFFO, Antonio Carlos; Ferrão, André Munhoz de Argollo. Indicadores de sustentabilidade em engenharia: como desenvolver. $1^{\mathrm{a}}$ ed. - Rio de Janeiro, Editora Elsevier, 2015.

GOMES, Luiz Flávio Autran Monteiro. Tomada de decisão gerencial: enfoque multicritério. São Paulo: Atlas, 2009.

GOMES, Luiz Flávio Autran Monteiro. Tomada de decisões em cenários complexos: introdução aos métodos discretos do apoio multicritério à decisão. Luiz Flávio Autran Monteiro Gomes, Marcela Cecilia Gonzáles Araya, Cláudia Carignano. São Paulo: Cengage Learning, 2011.

GOMES, Luiz Flávio Autran Monteiro; GOMES, Carlos Francisco Simões. Tomada de Decisão Gerencial: Enfoque Multicritérios. Luiz Flávio Autran Monteiro Gomes, Carlos Francisco Simões Gomes. $5^{a}$ edição, São Paulo: Atlas, 2014.

GUIMARÃES, Patrícia Borba Vilar; XAVIER, Yanko Macius De Alencar Xavier; LEMOS, Rafael Diogo Diógenes Lemos. Fundos Estaduais de Recursos Hídricos: a sustentabilidade econômica do sistema descentralizado de gestão. XVII Congresso Nacional do CONPEDI. Brasília, 2008. Anais...

GWP - GLOBAL WATER PARTNERSHIP. Agua para el Siglo XXI: de la Visión a la Acción para América der Sur. SAMTAC South American Technical Advisee Committe. GWP. 2000. Disponível em: <http://www.gwp.org/Global/The\%20Challenge/Resource\%20 material /FFA\%20regional\%20summary\%20SAM\%20Spanish. pdf>. Acesso: 01 set 2013.

INTERNATIONAL CONFERENCE ON WATER AND THE ENVIRONMENT. 1992. The Dublin Statement: Development Issues for the $2^{\text {st }}$ century. Dublin, Ireland, 1992. Disponível em: <http:// docs.watsan.net/Scanned_PDF_Files/Class_Code_7_Conference/ 71-ICWE92-9739.pdf>. Acesso: 01 set 2013.
KEENEY, Ralph L. Value-Focused Thinking: A Path to Creative Decision making. Harvard University Press, 1992.

MATZENAUER, Helena Barreto. Uma metodologia multicritério construtiva de avaliação de alternativas para o planejamento de recursos hídricos de bacias hidrográficas. 2003. Tese (Doutorado em Recursos Hídricos e Saneamento Ambiental). Universidade Federal do Rio Grande do Sul, Porto Alegre, 2003.

ROY, Bernard. Decision Science or Decision-Aid Science? European Journal of Operational Research, n 66, p 184 -203, 1993. Disponível em: <https://doi.org/10.1016/0377-2217(93)90312-B> Acesso em: jan 2019.

ROY, Bernard. Multicriteria Methodology for Decision Aiding Kluwer Academic Publischer: Dordrecht, 1996. 292 p.

SÃO PAULO (Estado). Decreto $\mathrm{n}^{\circ}$. 48.896, de 26 de agosto de 2004. Regulamenta o Fundo Estadual de Recursos Hídricos - FEHIDRO. Disponível em: < https://www.al.sp.gov.br/nor$\mathrm{ma} /$ ?id=51694> Acesso em: $14 \mathrm{mar} 2019$.

SÃO PAULO (Estado). Lei no. 7.663, de 30 de dezembro de 1991 Estabelece normas de orientação à Política Estadual de Recursos Hídricos bem como ao Sistema Integrado de Gerenciamento de Recursos Hídricos. Lex: Legislação de Recursos Hídricos - Consolidação, 2001. São Paulo, DAEE, 2002. p. 95-107.

SÃO PAULO (Estado). PERH - Plano Estadual de Recursos Hídricos 2004-2007. Relatório 1- Síntese dos Planos de Bacia. São Paulo, 2005.

SÃO PAULO (Estado). PERH - Plano Estadual de Recursos Hídricos 2016-2019. São Paulo: Secretaria Estadual de Saneamento e Recursos Hídricos, 2017.

SARTORI, Marcos Paulo Lallo. Governança na Bacia Hidrográfica do Alto Tietê: avaliação por critérios de investimentos. 2013. 122 f.. Dissertação (Mestrado em Engenharia Civil). Faculdade de Engenharia Civil, Arquitetura e Urbanismo - UNICAMP, Campinas, 2013.

SDM - SECRETARIA DE ESTADO DO DESENVOLVIMENTO URBANO E MEIO AMBIENTE (Santa Catarina). Plano Integrado dos Recursos Hídricos da Bacia do Rio Tubarão e Complexo Lagunar. Volume III - Plano de Uso Integrado dos Recursos Hídricos. Florianópolis, SC. 2002. 198 pp. Disponível em: < http://www.aguas.sc. gov.br/jsmallfib_top/DHRI/Planos\%20de\%20Bacias/Plano\%20 da\%20Bacia\%20Hidrografica\%20do\%20Rio\%20Tubarao\%20 e\%20Complexo\%20Lagunar/Volume\%20III/volume3.pdf> Acesso em: 18 set 2016 .

ZUFFO, Antonio Carlos e ZUFFO, Monica Soares Resio. Gerenciamento de Recursos Hídricos: Conceituação e Contextualização. $1^{\text {a }}$ ed. Rio de Janeiro, Editora Elsevier, 2016. 